\title{
"La jungla polaca": viaje a la Polonia comunista de la mano de Ryszard Kapuściński
}

\author{
Amelia Serraller Calvo \\ Universidad Complutense de Madrid \\ amelia.serraller@pdi.ucm.es
}

Recibido: $31 / 05 / 2013$

Aceptado: 10/06/2013

\section{RESUMEN}

No es un oficio común el de reportero, pues en él se confunden vida y obra. Ése es el caso del escritor y periodista Ryszard Kapuściński (1932-2007), que participó en los grandes debates de la Polonia comunista: la función de la poesía, el mito de Nowa Huta, la visión de las revoluciones latinoamericanas como la última gran esperanza, el nacimiento de Solidaridad, la caída de la URSS... La biografía Kapuściński non-fiction (2010), de Artur Domosławski, ha reabierto la discusión: ¿son sus obras reportajes o traspasan los límites del periodismo? Con el presente artículo no pretendemos encontrar una respuesta definitiva, sino destacar el interés de un autor que suscita tanta polémica.

Palabras clave: Revisionismo, historia y periodismo, reportaje, orientalismo, objetividad.

\section{"The Polish Bush": a Journey to Communist Poland Escorted by Ryszard Kapuściński.}

\begin{abstract}
Being a reporter is not a common profession, since life and work are intertwined. That is the case of Ryszard Kapuściński (1932-2007), the writer and journalist who took part in the great debates of Communist Poland: the function of poetry, the myth of Nowa Huta, the vision of the Latin American revolutions as the last great hope, the birth of Solidarity, the fall of the USSR ... The biography Kapuściński non-fiction (2010), by Artur Domosławski, has given way to a discussion around the following question: are his works mere reports or do they trespass the limits of journalism? In this article we do not intend to find a definitive answer, but to emphasize the interest of an author who is behind such a controversy.
\end{abstract}

Key words: Revisionism, History and Journalism, Reportage, Orientalism, Objectivity.

Sumario: 1. Introducción. 2. La peripecia vital y profesional de Ryszard Kapuściński. 3. Kapuściński, testigo del fin del colonialismo en África. 4. El imperio. 5. La cuestión de la objetividad. 6. Claroscuros de un intelectual comprometido. 7. Discusión de las hipótesis. 8. Conclusiones. 9. Bibliografía. 


\section{Introducción}

Resulta sumamente difícil clasificar la obra del polaco Ryszard Kapuściński (Pińsk, 1932-Varsovia, 2007). ${ }^{1}$ Periodista, viajero, poeta, fotógrafo, pensador ... fue un hombre polifacético que quiso elevar el reportaje a la categoría de literatura, experimentando con la mixtura de géneros. Sin embargo, a raíz de su muerte y de la aparición en 2010 de la biografía crítica de Artur Domosławski Kapuściński non-fiction, su legado y su vida están siendo objeto de una amplia revisión crítica, tanto en Polonia como en España y el mundo anglosajón.

¿Qué es entonces lo que hace a Kapuściński polémico? Su trayectoria y la recepción de su obra. Entre otras cosas, se le acusa de manipular la realidad y colaborar con los servicios secretos comunistas. De ahí que repasemos su biografía, incidiendo en sus inicios y en los aspectos más controvertidos de la misma. ¿Cambió a lo largo de los años el pensamiento del escritor y reportero? ¿Cómo sale reflejado su país en su obra? Al fin y al cabo, los estudios publicados no dejan de ser parte de la recepción de la misma. Por eso, como marco teórico hemos optado por la estética de la recepción y el modelo de Hans Robert Jauss, que distingue entre recepción pasiva, reproductiva y productiva.

A la luz de las fuentes primarias y secundarias parece evidente que el escritor y reportero es víctima de su propia fama, de una acogida entusiasta que le corona como uno de los grandes reporteros del siglo XX. La prensa y la televisión contribuyen a alimentar la leyenda del Kapuściński personaje público, víctima de una sobreexposición mediática y de operaciones editoriales que convierten sus charlas y entrevistas en inglés (idioma que no es su lengua materna) en libros. No es de extrañar que esa faceta del escritor y periodista, tan forzada, se resienta con el paso del tiempo. ¿Y por qué el último Kapuściński, teórico, analista y pensador, habría de quitar valor al grueso de su obra? Además, la polémica en torno a si cruzó los límites del periodismo es un debate apasionante, pero que no le resta atractivo a sus escritos, al tiempo que evidencia su riqueza formal. Y es que, tal y como demostraremos en nuestra investigación, su interés radica en su capacidad para generar controversia, que es clave en su vida y obra.

\section{La peripecia vital y profesional de Ryszard Kapuściński}

Kapuściński se inició como poeta dedicado a la agitación y a la propaganda políticas. El paso por la facultad de Historia de la Universidad de Varsovia y la posibilidad de

\footnotetext{
1 El presente artículo es la continuación de otros textos anteriores, como "La evolución ideológica de Kapuściński a la luz de su obra” o "En busca de un género nuevo. El Imperio de Ryszard Kapuściński”, publicados a lo largo del año 2011 en las revistas científicas Miguel Hernández Communication Journal y Eslavística Complutense respectivamente. Investigaciones que se inscriben en el marco de una tesis doctoral en fase de redacción, cuyo título provisional es La recepción de la obra de Ryszard Kapuściński en Polonia, Rusia y España: el caso de "El Imperio", bajo la dirección de la Doctora Agnieszka Matyjaszczyk Grenda. Una versión algo distinta de este texto se presentó en el simposio "Europa del Este durante el comunismo: aportaciones desde la historiografía española" que se celebró en la UCM los días 25 y 26 de octubre de 2013
} 
viajar por el Bloque del Este para cubrir los encuentros de las Juventudes Socialistas suponen un antes y un después en su obra. Son los años del deshielo, y en el periódico para el que trabaja, Estandarte de los jóvenes, los contenidos se van aligerando, hay sitio para el jazz y para las críticas cinematográficas. En ese clima aparece en Nowa Kultura en agosto de 1955 el Poema para adultos de Adam Ważyk, que ataca el gran símbolo de la Polonia de entonces, la construcción del barrio de Nowa Huta en Cracovia. A Kapuściński se le asigna la tarea de desmentir todas y cada una de las acusaciones de Ważyk, restaurando un mito al que él también había cantado cinco años atrás.

Por el contrario, el joven confirma una a una las escandalosas revelaciones. En su columna Esto también es cierto sobre Nowa Huta (To też jest prawda o Nowej Hucie número 234 de Sztandar Młodych), sólo discute con Ważyk acerca de la importancia de mantener altos la dignidad y el ánimo del trabajador. Ello no es óbice para que pida que se cree una comisión que mejore cuanto antes sus condiciones de vida.

Sabedor de las consecuencias que acarrearía su artículo, Kapuściński se camufló durante tres días entre los obreros cracovianos. Mientras, tanto su jefa como el censor del periódico fueron despedidos. Sin embargo, es tal la repercusión del texto, que la dirección del partido restituye en sus cargos a ambos, y otorga al joven periodista la Cruz de Oro al Mérito en 1956. Así recuerda el autor esta toma de conciencia en la compilación El mundo de hoy: "Aquella experiencia me insufló moral. Me hizo ver que escribir era arriesgarse, y que, en el fondo, no importaba tanto el hecho en sí de que se publicara un trabajo, como las consecuencias que se seguían. Cuando uno opta por describir la realidad, su escritura influye sobre esa realidad"'.

He ahí el porqué del éxito del periodista: su capacidad para generar controversia. Con sus siguientes encargos incorporará otro método de trabajo: la documentación y preparación previas. Inmediatamente después del escándalo de Nowa Huta se palpa el descontento que desencadenará las protestas de junio de 1956 en Poznań. Entonces su jefa, para protegerlo, lo envía a su primer gran destino: la India. Además, le regala un ejemplar de la Historia de Herodoto. El joven se siente desconcertado en una cultura tan exótica, con la barrera lingüística de por medio. Por eso se agarra a su formación universitaria y al libro, y se ve impelido a estudiar idiomas.

Además, aprende a sacarle partido a los imprevistos. El viaje a la India se alarga por el bloqueo del Canal de Suez. Esta circunstancia le obliga a volar a Kabul, donde se le detiene nada más bajar del avión ya que carece de visado. Una aventura que fructifica en sendos ciclos de reportajes: La ruta por Afganistán y La India desde cerca, que aparecen en El Estandarte en 1957. Sobre ella volverá también en su último libro, Viajes con Heródoto, un testimonio de su pasión por la vida, la historia y el periodismo.

2 KAPUŚCIŃSKI, Ryszard: El mundo de hoy, Autorretrato del reportero, Barcelona, Anagrama, 2004, p. 25 . 


\section{Kapuściński, testigo del fin del colonialismo en áfrica}

Volviendo a la atmósfera que se vivía en Polonia durante la segunda mitad de los cincuenta del pasado siglo, el nuevo comité de redacción de Estandarte de los jóvenes, elegido democráticamente por los trabajadores del mismo, es disuelto y sustituido por otro impuesto. Como muestra de repulsa, el grueso de la redacción del periódico, con Kapuściński entre ellos, lo abandona en marzo de 1958. Poco después, el joven periodista encuentra trabajo en la Agencia Polaca de noticias.

La primera incursión del escritor y reportero en África se produjo entre diciembre de 1959 y enero de 1960. Su base era entonces Ghana, aunque visitó además Dahomey (actual Benín) y Níger.

En esos años compaginaba sus viajes con su trabajo para Polityka, para la que recorría la provincia polaca escribiendo también reportajes. Esta concomitancia le permite mirar a su propio país desde otro ángulo, encontrar lo que éste tiene de sorprendente e insólito. De hecho, su obra es testimonio de un curioso trasvase, de un contraste buscado para encontrar una nueva óptica: Kapuściński nos muestra lo extraordinario de su propio entorno y el día a día de culturas exóticas.

Esta paradoja se pone de manifiesto en las referencias a Polonia que salpican su obra. A medida que su autor viaja, aquella es comparada con distintos países de diferentes continentes. Aunque esta operación se hace explícita en La jungla polaca, subtitulada Historias aventureras (Historii przygodne). Un motivo que le induce a adoptar esta perspectiva es la conciencia de su público. El lector modelo que tiene en mente Kapuściński es polaco hasta la segunda mitad de los ochenta del siglo veinte. Y si pensamos en sus grandes obras, hasta 1993 con la redacción de El Imperio.

La jungla polaca es justamente el pistoletazo de partida a su obra. A partir de 1962 el autor selecciona sus mejores textos y los publica en formato de libro. Sus mayores atractivos son el exotismo y la variedad. Así, Kapuściński aceptará nuevos destinos que sus compañeros rechazan, como África y América Latina, que se convierten en nuevos compromisos. En los años sesenta y setenta, cuando recorre ambas regiones, se convierte en uno de los pocos testigos de las grandes convulsiones de aquella época: la descolonización (Estrellas negras, de 1963; Si toda África, en 1969 y, posteriormente, Un día más con vida, de 1976, que es su primer libro unitario), el conflicto palestino-israelí, la guerrilla y la teoría de la liberación (Por qué mataron a Karl Von Spreti, de 1970; Cristo con un fusil al hombro, de 1975; La guerra del fútbol, de 1978, que él bautizó en la realidad y en la ficción).

Pese a las alabanzas de la crítica y a las múltiples reediciones, Kapuściński se cansa de repetir el modelo, en una nueva crisis creativa. De ella sale fortalecido, con una nueva temática: la tiranía del poder absoluto. Quiere escribir una trilogía sobre el tema, pero acaba escribiendo "sólo" dos obras, El Emperador, (1978) dedicado a Haile Selassie, y El Sha o la desmesura del poder (1982). Si bien en sus primeros libros comparaba constantemente los lugares que visitaba con Polonia, ahora esta práctica se vuelve mucho más sutil, se transforma en alegoría. Hay mecanismos y estructuras universales en toda dictadura o poder despótico. No hace falta irse tan lejos, si pensamos que cuando la crítica y los lectores suizos leían El Emperador, 
en vez de ver al Negus o a Edward Gierek se imaginaban al presidente de una gran multinacional.

Con el ocaso del régimen, la censura se recrudece y nuestro hombre devuelve el carnet del partido después de haber narrado en Apuntes costeros (1980) la historia in satus nascendi, la huelga de los astilleros de Gdańsk en la que nació Solidaridad, el primer sindicato libre en todo el Telón de Acero. En esas condiciones, se dedica a cultivar la fotografía, la poesía (ya evidentemente sin el corsé del realismo socialista) y el aforismo. Cae el comunismo y Kapuściński incorpora todo este bagaje en su próximo reportaje, El Imperio. El tema le resulta tan cercano como polémico, como veremos a continuación.

\section{El Imperio}

En el conjunto de una obra como la de Ryszard Kapuściński, engarzada con la peripecia personal, El Imperio marca el comienzo de una nueva etapa. Muchas son las razones que apoyan esta afirmación: con este reportaje, el periodista polaco retoma el género después de casi una década dedicado a otros menesteres; además, es el primer libro que redacta tras la caída del muro y por tanto libre de la censura.

Por todo ello, El Imperio en un texto complejo y de difícil clasificación. De hecho, es también fruto de la evolución ética y estética del historiador y reportero y del poso de esos años de búsqueda en otras disciplinas artísticas (la poesía, la fotografía y el aforismo), cuya huella es evidente en el libro que nos ocupa. De forma que continuidad y ruptura acaban siendo términos no excluyentes.

Así, de entre todas las definiciones que ha recibido, las más frecuentes y precisas son las de "reportaje autobiográfico" (según especialistas como Ziątek y Nowacka) y de "reportaje ensayístico" (acuñado por el propio autor y el periodista boliviano Raúl Peñaranda). Kapuściński dice al respecto:

El Imperio es precisamente un ensayo. Mi forma de escribir ha evolucionado hacia lo que denomino el reportaje ensayístico. Los ensayos conforman toda la buena prosa del siglo XX. La montaña mágica de Thomas Mann es un ensayo sobre el tiempo y la historia: el argumento es sólo el esqueleto que sostiene sus distintas partes. Actualmente, la prosa se bifurca en dos direcciones. Una de ellas es el ensayo, la otra es la ficcionalización. Lo mismo ocurre con el reportaje ${ }^{3}$.

Además de esas definiciones, debemos resaltar su parentesco con la literatura de viajes y su condición de obra no alegórica, a diferencia de El Emperador y El Sha.

Si queremos entonces profundizar en El Imperio, es indispensable ahondar antes en las intenciones de su autor. Afortunadamente, contamos con un buen número de testimonios valiosos acerca de la manera en la que se fue gestando El Imperio, la mayoría de ellos del propio Kapuściński. Así lo recordaba el inquieto autor en enero de 1993:

\footnotetext{
3 http://wyborcza.pl/kapuscinski/1,104867,7500834,Imperium.html. Si no se especifica lo contrario, todas las traducciones del polaco y del inglés son de la autora del artículo.
} 
A finales de los ochenta estaba trabajando en un libro sobre Idi Amin (...).Y precisamente allí, en Uganda, me di cuenta de lo rápido que se evapora la memoria histórica. (...). Mientras escribía, sin embargo, me bombardeaban las noticias sobre los cambios en la URSS y pude orientarme al respecto: allí estaban ocurriendo grandes cosas. Me decidí a viajar. Quería estar allí antes de que el tiempo borrara los detalles ${ }^{4}$.

En otras palabras, Kapuściński se decide a escribir sobre la Unión Soviética en 1988 porque quiere vivir en primera persona un gran acontecimiento que se avecina. Como periodista, sigue la actualidad, mientras que como historiador, que también es, indaga en las causas y consecuencias del suceso. Su concepción de la historia es muy afín a la de Tolstói y Unamuno, porque en ella se entrelazan los dramas individuales con los colectivos.

Sin duda, el asunto le atrapa por muchos motivos: se trata de un suceso de repercusión mundial, que coincide con el tema predilecto del reportero, el poder desmedido y su ocaso. Una fascinación que se explica por la coyuntura política internacional y por la biografía de Kapuściński. Y es que no es poca la huella que en su país y en su vida ha dejado la superpotencia vecina. Me refiero a su infancia, al trauma que supone la Segunda Guerra Mundial y la ocupación y posterior liberación de Polonia por parte de la URSS, además de sus estancias en ésta, particularmente la que en 1968 inspiró El kirguís baja del caballo. Dicho reportaje es un encargo que había recibido el periodista en el marco de las celebraciones del quincuagésimo aniversario de la Revolución de Octubre. En él describe su viaje por las repúblicas asiáticas del coloso soviético, que son las que dos décadas después desencadenarán la desintegración de la potencia. El resurgir del nacionalismo era patente en los distintos territorios soviéticos, tal y como en el 2001 lo rememoraba el escritor y periodista:

Amin era un tema completamente marginal en comparación con lo que ocurría en el Este. (...). En un principio mi plan era viajar siguiendo las huellas del libro El kirguis baja del caballo, esto es, a las repúblicas transcaucásicas y de Asia Central que pertenecían a la Unión Soviética y escribir qué es lo que allá había cambiado y lo que sucede actualmente. Al llegar allí me hice consciente de que aquello sucedía a escala de toda la potencia y que la estrecha ruta que me había trazado no bastaba para describirlo bien al completo. Me decidí a hacer varios viajes de envergadura por toda la Unión Soviética. Intentaba presentar la ruptura y caída del coloso soviético desde dentro. Era algo muy personal, ya que yo mismo procedo de las tierras fronterizas que desde 1939 forman parte del imperio soviético. Tenía pues una cierta sensación de estar obligado a escribir este libro 5 .

En esta ocasión, el reportero no sólo rescata del olvido la intrahistoria, los pequeños grandes dramas anónimos, sino que ahora también lucha para que el silencio no borre su propia historia. De hecho, ya en 1991 consideraba que las diecinueve páginas que consagra a su tierra natal en El Imperio no bastan para revivir un mundo

\footnotetext{
4 KALICKI, Włodzimierz: "Jak powstało Imperium”, Gazeta Wyborcza,19, 23-24 de enero de 1993, http://serwisy.gazeta.pl/kapuscinski/1,23084,457786.html

5 KAPUŚCIŃSKI, Ryszard: “Ryszard Kapuściński o książce Imperium”, Gazeta Wyborcza, Varsovia, 1 de enero de 2001, http://wyborcza.pl/kapuscinski/1,104867,7500834,Imperium.html
} 
perdido: "Algún día escribiré un libro sobre Pińsk, sobre la región de Polesie que ya no existe. Ésa es la fuente primordial de mis intereses"6.

De hecho, uno de los reproches que se le han hecho a El Imperio es la excesiva cantidad de temas y lugares que abarca, que derivan en la superficialidad. La rapidez con la que Kapuściński se desplaza será motivo de suspicacia para su compañero de oficio Mariusz Wilk (quien tilda El Imperio de "colección de postales" , siendo su método de trabajo absolutamente opuesto. Éste se basa en asentarse, vivir y asimilarse al lugar sobre el que se investiga), y para la crítico literaria y eslavista Maria Janion. Ello pone de manifiesto la divergencia entre su perspectiva y la del autor, que consideraba una heroicidad desplazarse en medio de un "imperio" colapsado:

La principal dificultad de este viaje era conseguir billetes de avión. Había una masificación terrible en todas las líneas. En 1990 Aeroflot no transportó en sus líneas domésticas a 22 millones de personas expectantes. Les faltaban aviones, pero la mayoría de las veces, petróleo. (...) La cantidad de tiempo para trabajar en los lugares concretos dependía a menudo de las plazas reservadas en los aviones, y no de mis planes.

Finalmente estuve en 15 repúblicas de la antigua URSS, recorrí en avión más de 60.000 kilómetros con las aerolíneas domésticas, (...) así que no podía permitirme un retraso, ni tampoco dedicar más atención a algo que me interesara. Todo el tiempo me preocupaba si tendría la siguiente conexión. Era esclavo de mi propio viaje ${ }^{8}$.

Cabe pues, preguntarse si, al reprochar a Kapuściński la falta de profundidad y sus continuos desplazamientos, se daban cuenta de lo difícil que le resultó al autor hacerlos. Otra motivación era escapar de los inacabables debates moscovitas, que no se traducían en medidas políticas concretas. Su presencia tiene también el valor del testimonio, fundamental en un reportaje:

La televisión me irritaba terriblemente. Toda la vida política se retransmitía entonces por televisión. En cada casa parpadeaban las imágines de las interminables asambleas del Sóviet Supremo. (...)

Mientras viajaba por el imperio intentaba estar todo el tiempo cerca de la gente. En diciembre del año 1990 estuve en la huelga de los mineros de Vorkutá. Si exceptuamos a un periodista del pequeño periódico local departamental, yo era el único periodista: no había nadie incluso de la prensa rusa. ¿Y qué puede escribirse sobre esas gentes de Vorkutá si ni siquiera se les ha visto? ¿Un ensayo?? .

6 MARSZAŁEK, Rafał: "Wschodni dywan", 6x9, 1, 1 de enero de 1991, http://www.kapuscinski.info/ wywiady/0,1991.html

7 Es muy elocuente al respecto la siguiente cita de WILK, Mariusz: Diario de un lobo. Pasajes del Mar Blanco, Alba, Barcelona, 2009, pp. 69-70: El método de Kapuściński es tan sencillo como un viaje turístico: un par de días en un sitio o en otro para hacer un capítulo imagen de cada lugar recóndito como una diapositiva de recuerdo. Está claro que es un escritor excelente y las imágenes que nos ofrece son espléndidas, sólo que... ¿para qué? ¿Para hacer un cómic sobre el imperio?

$8 \mathrm{http} / /$ wyborcza.pl/kapuscinski/1,104867,7500834,Imperium.html

9 V.V.A.A. (2008): Imperium. Postscriptum, Varsovia, Agora, p. 9. 
Su peregrinaje además le permite mantener una distancia hacia los cambios políticos que se suceden a un ritmo vertiginoso, que confunde y aturde. Una postura que vincula con la escuela de los Annales y con la importancia de distinguir entre procesos de larga y corta duración:

Es importante la escala temporal de los acontecimientos. Fernand Braudel escribió sobre ello desde una perspectiva historiosófica. (...) Hoy en día es necesario reflexionar sobre lo más duradero y recóndito: sobre la persistencia de Rusia, la persistencia del estalinismo, la continuidad de ciertas costumbres y formas de pensar. Occidente no entiende esto. De entre las publicaciones de las últimas veinticuatro horas (...) se puede llegar a la conclusión de que todo se reduce a la persona de Gorbachov. Esto es una visión muy extendida, pero superficial ${ }^{10}$.

Así pues, no queremos decir que las elecciones del escritor y reportero no sean criticables, sino que a Kapuściński le gustaban los desafíos, y decidirse a escribir $E l$ Imperio comporta para él un riesgo. Están en juego su credibilidad, su prestigio y su incipiente carrera internacional. Es evidente que su condición de corresponsal polaco que vino al mundo cerca de la frontera soviética le permite expresarse con fluidez en ruso, pero sus orígenes son también una especie de lastre.

De hecho, Kapuściński mismo es consciente de que la imagen de Rusia en Polonia y la de Polonia en Rusia están presididas por la animadversión, grabada a fuego por una historia de agresiones mutuas:

Toda la tradición literaria polaca, (Kamieński, Conrad, Brzozowski, Zdziechowski, y Żeromski) es una tradición que considera a Rusia como una amenaza, como algo peligroso, como un mal. Es similar la tradición de los polacos vistos por los autores rusos. Existe un precioso boceto de Maria Dąbrowska sobre el tema de los personajes polacos en la literatura rusa: salvo unas pocas excepciones, al polaco se le considera un rebelde, un anarquista, un hidalgucho, o como un espíritu maligno, un diablo. Toda la escritura de Dostoievski, Turguénev, Chéjov, Leskov, Gógol es, en ese sentido, muy ofensiva para los polacos. Así que la animosidad mutua caracteriza los cinco siglos que llevamos escribiendo unos sobre otros. (...) Rusia es nuestra obsesión, nuestro eterno problema $^{11}$.

\section{La cuestión de la objetividad}

Detrás de la polémica que ha levantado la biografía de Domosławski, subyace el gran debate sobre la frontera entre la literatura y el periodismo. En este caso, su autor no aporta casi ideas de su propia cosecha, sino que se limita a recoger todas las críticas ya existentes.

La discusión comenzó ya en el año 2001, cuando el crítico literario del Times Literary Supplement John Ryle enumeró las inexactitudes en los relatos que el escritor

10 http://kapuscinski.info/wschodni-dywan.html:

11 KAPUŚCIŃSKI, Ryszard: O ksiażkach, ludziach i sztuce, Varsovia, Czytelnik, 2009, pp. 164-165. 
polaco dedica a África ${ }^{12}$. He aquí la conclusión a la que llegó: "Las críticas no le restan al trabajo de Kapuściński el encanto de su inteligencia, sus momentos esclarecedores, o su viva simpatía, tan característica, por las gentes de los lugares de los que escribe, pero nos previenen a la hora de considerarlo seriamente como una guía de la realidad" $"$.

Para Timothy Garton Ash, historiador británico que es también especialista en Polonia, Ryle afirmaba que Kapuściński cultiva el denominado "barroco tropical", "un estilo en el que todo se vuelve más exótico, salvaje, descontrolado, extremo y, por qué no decirlo, oriental" ${ }^{14}$.

Por su parte, el escritor Salman Rushdie tiene una postura similar, sólo que más entusiasta y admirativa:

El único desacuerdo que he tenido con Kapuściński fue acerca de El Emperador, ya que, pese a su belleza (...), hay de todas formas una, como podría decirlo, cierta falta de respeto por los hechos (...). El libro acaba con una trágica - o conmovedora - imagen de Haile Selassie que, mientras muere en su cama, sigue creyendo que es el emperador de Etiopía. Cuando así no es como murió Haile Selassie. Fue estrangulado hasta la muerte por el régimen marxista que lo había vencido. (...) Se cuestiona la precisión de parte de lo que relata, pero nunca su belleza: ésta es incuestionable ${ }^{15}$.

Poco después apareció otra respuesta absolutoria, obra de Meghan O'Rourke, colaboradora de la revista literaria Slate. O'Rourke sostiene que el problema reside en la falta de etiquetas ante una nueva realidad como es la vertiente más literaria del periodismo. De todas maneras, afirma O'Rourke que "una aplicación demasiado rígida de esos criterios resultaría en un empobrecimiento del periodismo norteamericano que resulta impensable: parte del trabajo de los Nuevos Periodistas como Tom Wolfe, Gay Talese y Norman Mailer, iría directamente a la basura" ${ }^{16}$.

Por su parte, el reportero Jack Shafer habría de participar también de este incipiente revisionismo. Tan sólo dos días después de la muerte del escritor polaco, Shafer publicó igualmente en Slate un artículo en el que decía lo siguiente:

Algunos simpatizantes de Kapuściński quieren que entendamos su trabajo como una alegoría del lugar del que procede, la Polonia totalitaria. Como reportero de la agencia gubernamental no podía escribir la verdad sobre su país, así que utilizaba sus experiencias en Sudán, Etiopía, Angola, El Salvador, Bolivia, Irán y Chile entre otros

12 Al respecto habla GARTON ASH, Timothy: "La polémica creatividad de Kapuściński”, El País, Madrid, 12/03/2010, p. 33.

13 http://www.icees.org.bo/2013/04/the-lies-of-ryszard-kapuscinski/

14 Vid. nota 12.

15 WESCHLER, Lawrence: "Interview with Salman Rushdie”, Virginia Quaterly Review, volumen 84, número 1, invierno de 2008, p. 200.

16 O'ROURKE, Meghan: "Literary license. Defending Joseph Mitchell's composite characters", Slate Magazine, 29 de julio de 2003, http://www.slate.com/id/2086286/. Vuelto a publicar el 30 de enero de 2007, http://www.slate.com/id/2158496/pagenum/all/\#p2 : 
lugares, para hablar del día a día en Polonia durante el comunismo. Eso me parece bien, siempre y cuando nadie llame a su trabajo de campo periodismo ${ }^{17}$.

Transcurridos cinco días la misma publicación se hacía eco nuevamente del mencionado artículo de $\mathrm{O}^{\prime}$ Rourke, a fin de que sus lectores pudieran conocer las dos caras de la moneda, por así decirlo.

\section{Claroscuros de un intelectual comprometido}

La idealización del guerrillero, que en la flor de la vida se sacrifica por un ideal, es uno de los aspectos más polémicos de Cristo con un fusil al hombro (1975). A tenor de las cifras editoriales, se trata de uno de los reportajes de más éxito de Kapuściński en Polonia en su momento. Al respecto escribe Domosławski en un interesante artículo:

Kapuscinski está del lado de los protagonistas de sus relatos. Incluso cuando pregunta a unos combatientes palestinos por qué organizan acciones armadas en las que mueren civiles, comprende sus razones. Después del 11 de septiembre de 2001, a hombres así se los suele llamar "terroristas", a todos, al por mayor. Hace años se los llamaba "rebeldes", "partisanos", "guerrilleros"... El rebelde o el guerrillero es alguien que puede tener y esgrimir razones. El terrorista es un asesino que no merece ninguna comprensión ${ }^{18}$.

Tal y como expone la tesis del artículo, el reportero goza del prestigio internacional debido a que en muchas ocasiones no se comprende su mensaje. Éste es sumamente progresista y, por tanto, políticamente incorrecto.

En España, la aparición de la traducción de Cristo al castellano en febrero de 2010 fue seguida de un puñado de reseñas, entre las que llama poderosamente la atención esta crítica del escritor y periodista catalán Arcadi Espada, otrora devoto admirador de Kapuściński:

¿Qué morralla intelectual y política este último libro, Cristo con un fusil al hombro! Hay dos textos puramente espeluznantes: Por qué mataron a Karl von Spreti y Guevara y Allende. Von Spreti era embajador alemán en Guatemala y lo asesinaron terroristas de izquierda. Pero el gran Kapus no se amilana. No importa quién apretara el gatillo. Importa quien salió beneficiado. La Cia, desde luego ${ }^{19}$.

17 SHAFER, Jack: "The lies of Ryszard Kapuściński. Or, if you prefer, the magical realism of the nowdeparted master", Slate Magazine, 25 de enero de 2007, http://www.slate.com/id/2158315/ :

18 DOMOSŁAWSKI, Artur: "Kapuściński contra la manipulación", El País, 23/01/2008, http://elpais. com/diario/2008/01/23/opinion/1201042812 850215.html

19 ESPADA, Arcadi: "Solito en la vida. Kapuściński, El Cultural, 05/03/2010, http://www.arcadiespada. es/2010/03/18/kapuscinski/ 


\section{Discusión de las hipótesis}

Las posturas de Espada y Domosławski invitan a la reflexión: es cierto que Kapuściński no era ni mucho menos aquel anciano reportero provisto de un fino sentido común, pero demasiado buenista, tal y como lo presentaba la prensa en sus últimos días. Coincido pues con Domosławski en esta observación, pero podemos preguntarnos si acaso no sucede lo mismo con los autores famosos: su discurso se desvirtúa para que el conjunto de la sociedad lo asuma sin mayor esfuerzo ni reticencias.

Por otra parte, es muy interesante comparar la tesis de Arcadi Espada con la de Artur Domosławski. Aparentemente, ambos están constatando lo mismo, que Kapuściński está condicionado por la coyuntura política. Sin embargo, si rascamos un poco más, hallaremos una diferencia sustancial: Espada lo percibe como una cobardía moral, más que como una falta de agudeza; el biógrafo, por el contrario, incide en que su visión del mundo era la de un hombre de izquierdas, por lo que sus testimonios del pasado han dejado de ser políticamente correctos. Además, sus radiografías del presente (refiriéndose en concreto a su oposición a la guerra de Irak) deberían ser cuestionadas e impopulares en su país. De no ser porque el prestigio de su nombre las neutraliza.

Sin duda, tanto el análisis de Artur Domosławski como el de Arcadi Espada son verdaderamente interesantes, aun cuando resulte harto difícil pronunciarse sobre ellos. ¿Realmente podemos calibrar la honestidad con la que Kapuściński nos contó el despertar de América Latina en la década de los setenta?

\section{Conclusiones}

Como hemos visto, Kapuściński tiene un concepto intelectual del periodismo, en el que éste es una síntesis de las más diversas disciplinas destinada a perdurar.

Kapuściński no es el primer escritor y periodista (ni será tampoco el último) cuyo prestigio se pone en entredicho: antes que él Truman Capote, Hunter S. Thompson y Gabriel García Márquez, entre otros, han sido objeto de similares críticas.

Realmente, nuestro objeto de estudio logra equilibrio entre la heterodoxia y la corriente dominante. Si su pensamiento fuera radical habría sido rechazado de pleno por el mainstream, mientras que un trabajo convencional haría bostezar a los lectores. El periodista polaco ha tenido pues la habilidad de estar en el ojo del huracán (aún ahora, ya fallecido, lo consigue), lo que es señal inequívoca de olfato y de cierta independencia creativa.

Consciente de estas reticencias, él mismo explicó en un encuentro que recogió Pedro Sorela el 14 de diciembre de 1990 para El País, que "la objetividad es una meta. Como en filosofía, la buscamos pero jamás la conseguimos plenamente". En ese momento el cronista del acto recuerda que para Tom Wolfe y los teóricos del Nuevo Periodismo "la realidad es tan rica que escribir es siempre escoger". De ahí que siempre haya algo que se pierda en el camino. Sirva el ejemplo de Kapuściński, viajero audaz, explorador de su oficio. 


\section{Bibliografía}

\section{a) Fuentes primarias}

KAPUŚCIŃSKI, Ryszard: Czarne gwiazdy, Varsovia, Czytelnik, 1963.

KAPUŚCIŃSKI, Ryszard: Dlaczego zginat Karl von Spreti?, Varsovia, Czytelnik, 1970.

KAPUŚCIŃSKI, Ryszard: Gdyby cała Afryka, Varsovia Czytelnik, 1971 (1ª edición, 1969).

KAPUŚCIŃSKI, Ryszard: Kirguiz schodzi z konia, Varsovia, Iskry, 1974 (1ª edición, 1968).

KAPUŚCIŃSKI, Ryszard: Lapidaria IV-VI, Varsovia, Agora, 2008.

KAPUŚCIŃSKI, Ryszard: O ksiażkach, ludziach i sztuce. Pisma rozproszone, Varsovia. Czytelnik, 2009.

KAPUŚCIŃSKI, Ryszard: „Ryszard Kapuściński o książce Imperium”, Gazeta Wyborcza, Varsovia, 1 de enero de 2001, http://wyborcza.pl/kapuscinski/1,104867,7500834,Imperi um.html

KAPUŚCIŃSKI, Ryszard: El Sha o la desmesura del poder, Barcelona, Anagrama, 1987.

KAPUŚCIŃSKI, Ryszard: El Emperador, Barcelona, Anagrama, 1989.

KAPUŚCIŃSKI, Ryszard: La guerra del fútbol y otros reportajes, Barcelona, Anagrama, 1992.

KAPUŚCIŃSKI, Ryszard: El Imperio, Barcelona, Anagrama, 1994.

KAPUŚCIŃSKI, Ryszard: Ébano, Barcelona, Anagrama, 2000.

KAPUŚCIŃSKI, Ryszard: Los cínicos no sirven para este oficio, Barcelona, Anagrama, 2002.

KAPUŚCIŃSKI, Ryszard: Un día más con vida, Barcelona, Anagrama, 2003.

KAPUŚCIŃSKI, Ryszard: Lapidarium IV, Barcelona, Anagrama, 2003.

KAPUŚCIŃSKI, Ryszard: El mundo de hoy. Autorretrato de un reportero, Barcelona, Anagrama, 2004.

KAPUŚCIŃSKI, Ryszard: Viajes con Heródoto, Barcelona, Anagrama, 2006.

KAPUŚCIŃSKI, Ryszard: Encuentro con el Otro, Barcelona, Anagrama, 2007.

KAPUŚCIŃSKI, Ryszard: La jungla polaca, Barcelona, Anagrama, 2008.

KAPUŚCIŃSKI, Ryszard: Poesía completa, Madrid, Bartleby, 2008.

KAPUŚCIŃSKI, Ryszard: Cristo con un fusil al hombro, Barcelona, Anagrama, 2010.

\section{b) Fuentes secundarias}

CAPOTE, Truman: A sangre fría, Barcelona, Anagrama, 2009.

DOMOSŁAWSKI, Artur: „Kapuściński contra la manipulación”, El País, 23/01/2008, http://elpais.com/diario/2008/01/23/opinion/1201042812_850215.html

DOMOSŁAWSKI, Artur: Kapuściński: Non-Fiction, Barcelona, Galaxia Gutenberg-Círculo de Lectores, 2010.

ESPADA, Arcadi: "Solito en la vida. Kapuściński”, El Cultural, 26/04/2013, http://www. elcultural.es/version_papel/OPINION/32703/Solito_en_la_vida 
GARTON ASH, Timothy: "La polémica creatividad de Kapuściński”, El País, 12/03/2010, p. 33.

MANN, Thomas: La montaña mágica, Barcelona, Edhasa, 2004.

NOWACKA, Beata y ZIĄTEK, Zygmunt: Ryszard Kapuściński. Una biografía literaria, Madrid, Bibliópolis, 2008.

ORZESZEK, Agata (coord.): Viajes con Ryszard Kapuściński, Bellaterra, UAB, 2008.

RUSHDIE, Salman: El suelo bajo sus pies, Barcelona, Plaza y Janés, 1999.

TOLSTÓI, Lev Nikoláievich: Guerra y paz, Barcelona, El Taller de Mario Muchnik, 2004.

WILK, Mariusz: Diario de un lobo. Pasajes del Mar Blanco, Barcelona, Alba, 2009.

WOLFE, Tom: El Nuevo Periodismo, Barcelona, Anagrama, 1977.

HOCHSCHILD, Adam: Finding the Trapdoor: Essays, Portraits, Travels, Syracuse (Nueva York), Syracuse University Press, 1997.

O'ROURKE, Meghan: “Literary license. Defending Joseph Mitchell's composite characters”, Slate Magazine, 29 de julio de 2003, http://www.slate.com/id/2086286/. Vuelto a publicar el 30 de enero de 2007, http://www.slate.com/id/2158496/pagenum/all/\#p2

SHAFER, Jack: "The lies of Ryszard Kapuściński. Or, if you prefer, the magical realism of the now- departed master", Slate Magazine, 25 de enero de 2007, http://www.slate.com/ $\mathrm{id} / 2158315 /$

WESCHLER, Lawrence: “Interview with Salman Rushdie”, Virginia Quaterly Review, número 1, volumen 84, invierno de 2008,

BERES, Witold y BURNETKO, Krzysztof: Kapuściński: nie ogarniam świata, Varsovia, Świat Książki, 2007.

DUDKO, Bożena (coord.): Podróże z Ryszardem Kapuścińskim, część II. Opowieści czternastu tlumaczy, Cracovia, Znak, 2009.

DUDZIAK, Arakadiusz y ŻEJMO, Agnieszka: Ryszard Kapuściński-Wizja świata i wartości. Refleksje interdyscyplinarne, Olsztyn, Vertum, 2009.

GÓRECKI, Wojciech: „Reportaż i trwanie. Rozmowa z Ryszardem Kapuścińskim”, Res Publica Nowa, 7-8, 1993, pp. 55-59.

KALICKI, Włodzimierz: „Jak powstało Imperium”, Gazeta Wyborcza, 19, 23-24 de enero de 1993, http://serwisy.gazeta.pl/kapuscinski/1,23084,457786.html

KUNCE, Aleksandra: Antropologia punktów. Rozważania przy tekstach Ryszarda Kapuścińskiego, Katowice, Wydawnictwo Uniwersytetu Śląskiego, 2008.

KURCZAB-REDLICH, Krystyna: Pandrioszka, Varsovia,Twój Styl, 2000.

ŁOPIEŃSKA, Barbara: „Człowiek z bagna”, Przekrój, 13 de julio de 2003, http://www.kapuscinski.info/zyciorys/14,czlowiek-z-bagna.html

MARSZAŁEK, Rafał: “Wschodni dywan”, 6x9, 1, 1 de enero de 1991, http://www.kapuscinski.info/wywiady/0,1991.html

MROZIEWICZ, Krzysztof: Prawdy ostateczne Ryszarda Kapuścińskiego, Varsovia, Sensacje XX Wieku, 2008.

SOKOŁOWSKI, Marek: Ryszard Kapuśćiński. Próba portretu, Varsovia, WSP TWP, 2008.

V.V.A.A.: Imperium. Postscriptum, Varsovia, Agora, 2008.

WOLNY-ZMORZYŃSKI, Kazimierz: O twórczości Ryszarda Kapuścińskiego: próba interpretacji, Rzeszów, Libri Ressoviensis, 1998. 
WOLNY-ZMORZYŃSKI, Kazimierz: Wobec świata i mediów. Ryszarda Kapuścińskiego dylematy dziennikarskie, literackie, społeczno-polityczne, Cracovia, Wydawnictwo Uniwersytetu Jagiellońskiego, 1999.

WOLNY-ZMORZYŃSKI, Kazimierz: Ryszard Kapuściński w labiryncie współczesności, Cracovia, Wydawnictwo Uniwersytetu Jagiellońskiego, 2004.

WOLNY-ZMORZYŃSKI, Kazimierz (coord.): Ryszard Kapuściński: portret dziennikarza i myśliciela, Opole, Wydawnictwo Uniwersytetu Opolskiego, 2008.

WRÓBLEWSKI, Bogusław (coord.): Życie jest z przenikania...Szkic o twórczości Ryszarda Kapuścińskiego, Varsovia, Państwowy Instytut Wydawniczy, 2008. 